\title{
Planned Obsolescence: Is It a Trap Set for the Consumer or Is It a Strategy Contributing to Social Development?
}

\author{
Esra KARAKUȘ UMAR ㅇ, Rafet BEYAZ² @
}

\begin{abstract}
Planned Obsolescence, which is a controversial concept with its positive and negative criticism in the literature, is a concept that refers to the limited life span of products. It attracts the attention of researchers that the concept is both identified with consumption culture and seen as an important development tool. Based on the question of "Is planned obsolescence a socioeconomic opportunity or a trap for consumers?" it is aimed to reveal the approaches of the experts in this study.

Based on the qualitative research design semi-structured, in-depth interviews were conducted with 21 experts. As a result of the study generally two approaches of the interviewers towards the concept of planned obsolescence can be mentioned. According to the first approach, planned obsolescence is considered as a necessary and ethical concept for social, economic, technological and ecological development. Planned obsolescence has been "positively" received in that it allows consumers to get rid of repair and maintenance costs and lower income groups to access services. According to the second approach, planned obsolescence is considered as the sum of characteristics that pollute the environment, exploit consumers, waste resources and push people to crime.
\end{abstract}

Key Words: Planned Obsolescence, Consumption Culture, Marketing, Economic Development, Qualitative Method

Jel Codes: M30, M39

\section{INTRODUCTION}

Culture is the sum of all the material and spiritual content that a society makes in everyday life. Cultural elements reveal patterns between the behaviors of members. A new set of behaviors emerge as a new cultural element with the approval of society after certain repetitions. While saying that culture is a living element, Fiske (1999: 35) mentions its variable feature. With globalization, similarity in cultural characteristics has emerged. The characteristics of local culture began to melt among the characteristics of other cultures. This situation, conceptualized as glocalization, represents the harmony of global contents within local culture (Robertson, 1995:28).

As globalization creates macro effects, glocalization creates micro and unique effects. All these effects serve a single purpose, namely the globalization or glocalization of consumption. The resulting general situation implies that the contents and meanings of the consumption culture change in different social structures, but the general structure, namely the "behavior of directing individuals to continuous consumption" remains the same.

Consumption culture does not have a style that appeals to individuals. It is a system that forces individuals to perform certain behaviors (Baudrillard, 2015:95). The expression of coercion here involves directing individuals into the act of re-consumption with a program developed against their background, not an apparent behavior. As individuals take the act of consuming, as in a rewarding system, they are rewarded. Reward, on the other hand, refers to a temporary feeling of pleasure. 
Thus, individuals become constantly consuming in an area whose boundaries become uncertain as it expands (Ferguson, 1996:2005; Featherstone, 2013:38-19; Bocock, 2014).

Individuals may think they consume certain meanings while consuming (Levy, 1959). For example, seeing the purchase of an object as a necessity is not enough for a consumer culture. Therefore, there is a system in which the individual will be "excluded" when he / she does not consume it. In that case, the individual can see the object as a need not only because he/she needs it, but also because he knows that he will be excluded when he does not consume. While the individual attributes new meanings to objects and turns them into a constant consumption material, Bauman (2018: 250) states that "this cannot be called consumption anymore, it can be called" consumerism".

Here, the concept of planned obsolescence appears as a situation that addresses the individual's" consumerism " behavior and restores the individual to pre-consumption desires the concept of planned obsolescence means that every object of consumption has a life span. It does not matter how much the consumption object has been used until then. Thus, the consumer can consume the new one a little earlier (Smeels and Stevels, 2003). Since the strategy of the producer to produce and sell more depends on the consumer demand, it is a situation that the producer wants to make the product unusable and the consumer to buy the same product again (Çerçi, 2019). In this way, the manufacturer increases his/her profit (Slade, 2006).

The concept of Planned Obsolescence has become expressed by new conceptualizations as it has been studied. While Cooper (2004a) uses the concept of "relative obsolescence", Smeels and Stevels (2003) define it as "product renewal". Nes, Cramer and Stevels (1999) made changes in the types of planned obsolescence using the concept of "change decision model" in their papers. Also, planned obsolescence has different types in itself. Packard (1960) mentions three types of planned obsolescence in his book "Waste Makers". The first is the functional obsolescence of the product. An advanced type of product is being released, while the old model is becoming obsolete. Second, it is aging, which is called quality obsolescence and refers to the deterioration of the product. The third type of obsolescence is attraction obsolescence (psychological obsolescence). The product can be replaced with another product that is more attractive to the consumer.
In this study, while the concept of "planned obsolescence" is defined, the types of planned obsolescence are expressed over three types as in Cooper (2004a)'s study. Accordingly, it is accepted that planned obsolescence is carried out in the form of psychological, technological and finally economic obsolescence. There is an abstract obsolescence in psychological obsolescence. Although apparently the product is still in good condition, it is no longer attractive to the consumer and the consumer wants to change the product. Hayes (1978) defines psychological obsolescence from a consumer perspective, saying that "most design changes are made not to improve the product aesthetically or functionally, but to wear it out." Even Bauman (2017) makes a mocking interpretation of psychological obsolescence by speaking in a humorous way, saying "What were we supposed to do, fall behind the age?" Nes, Cramer, and Stevels (1999: 3)'s definition of aesthetic obsolescence can also be included in this definition. Aesthetic obsolescence can also be defined as the fact that the product is not aesthetic or fashionable from the point of view of the individual.

The situation in question in technological aging is related to the fact that it is not rational for the consumer to hold the product. With technological developments, it can be said that today's technological products develop new performances with new versions and updates, causing consumers to buy new products. Therefore, there is a situation where the product that has been released is obsoleting the product in the hands of the consumer.

Finally, in economic aging, there are situations where the use of the product does not provide any benefit to the consumer. Economic costs created by the product or the inability of the product to create savings can be cited as an example of economic obsolescence (Cooper, 2004a). This condition was named as technical obsolescence by Nes, Cramer and Stevels (1999). So much so that the product cannot provide the consumer with what it promises in a technical sense.

First of all, a literature review introducing the current literature from a broad perspective is included in the research. The concept of planned obsolescence has been defined and at the same time different types of planned obsolescence are emphasized. This field of study is important for the compilation of the existing literature. As a matter of fact, the concept of planned obsolescence and the working area of planned obsolescence is not a field that is frequently studied. This situation presents the importance of the study. Moreover, the study is not 
just a literature review. In the other part of the study, the experiences of the individuals regarding the concept are included.

The aim of the study is both to open a door with a qualitative research design that includes the experiences of the consumer and to reveal how "planned obsolescence" is evaluated in terms of consumers as a strategy that production centers can prefer. It was aimed to ask the interviewers what the concept of planned obsolescence was in the study to reveal the meanings created by such a strategy.

\section{LITERATURE REVIEW}

In general, two approaches to the concept of planned obsolescence appear when the literature is examined. In the first approach, planned obsolescence contributes to more profit for businesses, while causing consumers and societies to experience significant problems. According to this approach, consumers and society are made dependent and exploited, resources are wasted and significant environmental problems arise. (Sihvonen, 2020; La Rosa, 2020; Albrecht, 2019; Latouche, 2009; Proske et al., 2016; Malinauskaite and Erdem, 2021; Zhao et al., 2021; Özkan and Yücel, 2020; Marcus, 2020; Kuppelwieser et al., 2019; Paricio et al., 2019; Adrion and Woidasky, 2019). In the second approach, planned obsolescence is considered as a concept that provides various benefits to both producers and consumers and society. According to this approach, planned obsolescence, when well-constructed, is considered as a concept that contributes to the development of technology, the reach of products and services to the entire audience, the reduction of environmental pollution and economic development (Grout and Park, 2005; Akçay, 2018; Strausz 2009; Kessler and Brendel, 2016; Erdil and Taçgın, 2019; Fishman et al., 1993; Visseren, 2019; Sielska, 2019). Some studies conducted in this context are evaluated below.

Within the scope of the first approach, La Rosa (2020) considered planned obsolescence as a harmful approach due to both the irrational use of natural resources and the constant repair and repurchase of consumers. In this context, various evaluations have been made on whether it would be a deterrent to evaluate this phenomenon as a type of crime. In a similar study, Albrecht (2019) stated that extending product lifetimes is an important factor in ensuring ecological balance. In addition, it is stated that the planned obsolescence, which is used only to increase the profits of producers, is unacceptable during the climate crisis and when the resources are exhausted, and in this case, the phenomenon can be evaluated within the scope of public law and even criminal law. Latouche (2009), on the other hand, showed that there is an endless consumption frenzy in a world where resources are limited and the main reasons of this situation are planned obsolescence, advertisements and credits. Investigating the underlying reasons for the life cycle of smart phones and planned obsolescence, Proske et al. (2016) found that a significant portion of consumers believed in the reality of planned obsolescence in the market and wanted to have more durable products. Malinauskaite and Erdem (2021), evaluating planned obsolescence from three different perspectives (demand side, supply side and environmental side), stated that existing measures to deal with planned obsolescence are insufficient in terms of unfair competition and consumer protection law, competition law and environmental law. They expressed the need for EU measures prohibiting planned obsolescence. Zhao et al. (2021) stated that planned obsolescence endangered consumers unnoticed and that measures to solve this situation could not be developed yet. Sihvonen (2020) stated that planned obsolescence, which aims to stimulate consumption, is harmful for both users and the environment. Özkan and Yücel (2020), on the other hand, evaluated the planned obsolescence phenomenon within the scope of linear and circular economy and made suggestions at the point of sustainability. In this context, other studies evaluating the negative aspects of the concept of planned obsolescence are as follows: (Marcus, 2020; Kuppelwieser et al. 2019; Paricio et al., 2019; Adrion and Woidasky, 2019; Satyro et al. 2018; De Franceschi, 2018).

Cooper (2008b) proposed a preliminary model to show that sustainable consumption requires longer-lasting products since less products, services and more efficient materials and energy are required to adequately reduce environmental problems. An attempt has been made to show how products with longer product life can secure the progress towards sustainable consumption, contributing to efficiency and competence. With a similar approach, Echegaray (2016) evaluated product obsolescence as an important challenge in terms of sustainability and stated that such applications are seen especially in the electronics industry and create a significant waste problem. Bianchi (2018) and Guiltinan (2008) stated in their study that the concept of planned aging used to maintain consumption culture will increase the use of natural resources. It was stated that with this increase, new products will be produced and old products will become waste and thus important 
environmental problems will arise. Maitre - Ekern and Dalhammar (2016) and Sherif and Rice (1986) stated in their studies that improving product durability and reparability can save natural resources and money for consumers, but this may not always be beneficial for all manufacturers.

In the context of the second approach, Grout and Park (2005) stated that planned obsolescence revitalizes the second-hand market and provides the opportunity to meet the expectations of consumers who want low quality-affordable prices and high quality-high prices (Akçay, 2018; Strausz 2009). In addition to providing a condition (Kessler and Brendel, 2016) and contribution to technological progress (Erdil and Taçgın, 2019; Fishman et al., 1993), it is also stated that it can provide various benefits such as reduced costs, cheaper use of parts, increased mature sales and mass production (Erdil and Tangıç, 2019). After all, when products are durable, potential innovators may lack incentives to develop a new technology. This can cause the economy to stagnate (Fishman et al., 1993). Sielska (2019) stated that planned obsolescence has both positive and negative consequences for consumers.

Apart from the two approaches mentioned, different studies related to planned obsolescence can be reached. In this context, Gecit (2020) researched key concepts related to planned obsolescence and identified 28 keywords that were collected under 5 dimensions as a result of this research. Neckel and Boeing (2019) found in their study that innovativeness behavior has an important and positive effect on the planned obsolescence process. Franzolin (2020) analyzed the concept of planned obsolescence within the scope of sustainability and evaluated the consumer rights within this scope. There are various studies on this subject, which is among the popular topics of recent time (Kamenar, 2020; Becher and Sibony, 2020; Philip, et al., 2020; Kuik and Diong, 2019; Kinokuni, et al., 2019; DiMatteo and Wrbka, 2018; Milchev, and Miltchev, 2018; Brönneke, 2017).

\section{METHOD}

The area called society is equipped with some objective structures and rules that existed before individuals. These rules regulate or control the social life of individuals. There is also a subjective side of society. In this field, individuals rebuild the society by displaying certain behaviors when they encounter social rules. In a sense, society can be explained with a relational approach that can be understood by focusing on both the structure and the individual.

In society, it is predictable how individuals will behave under certain circumstances. By looking at the reasons that are seen as the cause of actions, the social structure is understandable and predictable. Individuals are in a constant struggle in social life. The aim in this struggle is to seize power. Whoever holds the power can hold the power through constant struggle.

Individuals struggle for "power", but what power is determines the nature of this struggle. As in the subject of our study, "power" in consumption culture is about being able to consume more. In that case, it will be the desire to "consume more" that directs the actions of individuals. In terms of seeing this understanding process and the effect of the structure, the study has been set out from a qualitative perspective. Within the scope of these interviews, determining the general nature of the attitudes towards the concept of planned obsolescence was determined as the main goal. The main question of the research is in the semantic world of the interviewees is as follows: "Planned obsolescence: Is it a trap for the consumer or a strategy that contributes to social development?"

In-depth interviews were conducted with twenty-one experts in economics, business, mathematics, sociology and engineering in Turkey using the purposeful sampling technique. While choosing the interviewees, care was taken that their economic status was not different from each other. Gender or age was not determined as a variable, but emphasis was placed on the interviewers being experts in the field. Interviews lasted 1 to 1.5 hours. It was preferred to interview the interviewees at their workplaces. Semi-structured questionnaires were used and the interview was advanced with some additional questions in the expressions that required deepening. In the questionnaire used in the interviews, four questions are demographic questions aiming to get to know the interviewer. The remaining nine questions are about the concept of "planned obsolescence". As the profoundness of the questions increased during the interviews, the number of questions also increased. The opinions of the interviewees regarding the existence of planned obsolescence were fundamentally questioned in the formation of the questions. It is an important detail that there are academicians among the interviewees who have a good command of the field. Thus, the concept of planned obsolescence has been examined in terms of both the producer and the consumer. No action has been taken from question 
forms in the literature, as research with this design is not included in the literature. The interviews were recorded with a tape recorder.

In the data analysis phase, three main themes were used in order to evaluate qualitative data under certain themes in terms of "meaning". "The approach intended for planned obsolescence", "consumption habits" and "new and old ideas", themes were supported by categories and subcategories. During the analysis of the data, Atlas.Ti8 program was used. As a result, in this study in which the concept of "planned obsolescence" was questioned, clues about the "acceptations and approaches" produced by the interviewees were sought.

\section{FINDINGS}

The themes used during the analysis of the interview data were used in the outline of the findings. Accordingly, the theme" The Approach Intended for Planned Obsolescence" was detailed under the title of "Expert Opinions on the Concept of Planned Obsolescence". Secondly, the data regarding the "Consumption Habits" theme were presented under the title of "Planned Obsolescence Continues as It Suits the Manufacturer and Consumer". Finally, experiences related to the"new and old ideas" theme were presented under the title of "When It Fails, We First Check to See If There Is A Way to Repair It".

\section{Expert Opinions on the Concept of Planned Obsolescence}

During the interviews, in-depth interviews were conducted with interviewers who are experts in their field. The views and experiences of the interviewers specialized in business, economics, sociology and engineering on the concept of "planned obsolescence" were used. As a result of the interviews, it was seen that only five interviewees heard the concept of planned obsolescence and developed an idea about this concept. Other interviewees stated that although they did not hear the name of the concept theoretically, they were informed about its meaning.

11 (Male, 39), 121 (Male, 35), who specialize in business science at a university, and 117 (Female, 48), 118 (Female, 32) and I20 (Male, 37), who specialize in engineering stated that they heard the concept of "planned obsolescence" before. "I1" (Male, 39) defined planned obsolescence as "manufacturers can produce much more durable products under normal conditions, while creating more unstable products to resell the same products to the same customers". The interviewer emphasized that products are made "unstable" and this situation causes individuals to "consume" more. 121 (Male, 35) stated that planned obsolescence is an understanding that aims to continuously sell goods to them by reducing the life of products and manipulating consumers. 117 (Female, 48) considered it as a concept that exploits resources, causes environmental pollution, negatively affects sustainable development, and impoverishes the society. 118 (Female, 32) stated that with planned obsolescence, consumers become dependent on producers and become slaves of consumption. This situation creates various financial problems especially for consumers and forces them to work in unsuitable conditions with lower wages. Thus, people lose their self-identity, become depressive, and start using various drugs. Stating that the concept generates both positive and negative results, 120 (Male, 37) stated with a remarkable statement that planned obsolescence is one of the most important factors that push people to crime. The interviewer stated that the tendencies of extortion, theft, fraud, bribery, counterfeiting, smuggling and using backstreet products, which have increased rapidly in recent years, emerged as a result of the deterioration of spiritual and intellectual values that emerged as a result of the planned obsolescence concept.

13 (Female, 30), who said that she had not heard of the concept of "planned obsolescence" before but could make a guess about it, defined planned obsolescence as a concept that can be perceived in parallel with the concept of depreciation with these words: "I've never heard of it, but it may be depreciation of a product. The concept of depreciation is used in accounting. You estimate in how many years a property will wear out. You reap an economic life on a property. In fact, you know how much the product can be used in production." In this context, I 3 (Female, 30) has used the concept of wear out to emphasize "being durable" as I1 (Male, 39). 12 (Male, 27), evaluating the concept of planned obsolescence within the framework of the concept of depreciation, expressed it as "estimating the life of the products" as I3 (Female, 30).

Stating that he does not know what planned obsolescence is, 16 (Male, 27), when he heard the definition of the concept of planned obsolescence, he mentioned that such a planning can be done in the production process. He mentioned that the concept of "planned obsolescence" can be considered as a "marketing strategy" or a tactic towards the market, which can be very important in terms of marketing the products. 
Likewise, engineer 14 (Male, 31), who works in a sector far from marketing relations, stated that he did not hear the concept of planned obsolescence and made a guess about the concept. According to him, the reason of the planned obsolescence may be "... While new models of mobile phones are constantly being released, what you have may be old models". Explaining planned obsolescence based on the concept of "being old fashioned" of the product, the interviewer evaluated the phenomenon as "a necessary condition for the development of technology" and highlighted the positive side of the concept. I19 (Male, 34) made a similar statement and stated that planned obsolescence is an important concept in terms of catching up with developing technology and especially in order to reach the level of developed countries, it is necessary to implement a policy within this framework. In addition, the interviewer deemed planned obsolescence necessary by saying "the more consumption increases, the more production increases. This increase in production contributes to social and economic development".

Referring to both the positive and negative aspects of the concept of planned obsolescence, I20 (Male, 37) stated that it can make an important contribution to follow technological developments and ensure economic development, and thus social development can be achieved.

Mathematics teacher 17 (Female, 35), who is far from the relations of production and consumption planning, said that she had not heard of such a concept and that she could only make such a decision herself. She stated that "Who can decide how long my product can be used? What if I don't have enough money? It doesn't make any sense. "and emphasized the negative side of planned obsolescence. Like some interviewees, 17 (Female, 35) argued that planned obsolescence would not make any sense at all.

In this context, it can be stated that the concept of planned obsolescence is a concept that is not exactly known even by people who are experts in the field of Business, Economics, Mathematics, Engineering and sociology. But while they did not have ideas about conceptualization, a significant part of the interviewees suggested that they considered planned obsolescence possible and reasonable, and that this could be a market-related tactic. However, some interviewers have stated that they perceive the concept completely negatively and that it has serious problems both socially and individually.

\section{“Planned obsolescence continues as it suits the manufacturer and consumer."}

In general, some interviewers considered the concept of planned obsolescence as a phenomenon that should be used in the production process, while some interviewers stated that it is a concept that harms consumers and society. In this context, 12 (Male, 27) said: "A 5-year product may have a 10-year performance. This leads to insatiable consumption. If a time period is to be determined, this should be done with very professional techniques." The interviewer stated that the innovations to be made should make a meaningful contribution to society without harming the consumer and wasting resources.

As stated by 12 (Male, 27), 14 (Male, 31), also opposed the idea that planned obsolescence is necessary as a contribution to technology.

"This time, we will have overproduced and therefore will necessarily want to sell these extra products; because it has a cost. We will try fraudulent things when we can't find a buyer when we want to sell."

Underlining that the positive side of planned aging for the producer is also positive for the consumer, 18 (Male, 35) tried to justify the reason for the planned aging with the following statements: "...We no longer want to use a product we bought for years, we get bored. ..."

While explaining the positive side of planned obsolescence when evaluated from the consumer point of view, 19 (Female, 37), argued that planned obsolescence behavior is appropriate with the following sentences: " When we got married, we bought sitting groups that we could not sit down or use comfortably because they were dowry. We want to change them when we move to ournew home. "While I1 (Male, 39) claimed that consumers are bored and planned obsolescence is already necessary, he claimed that planned obsolescence is a side that appeals to consumers with the following statements:

"For example, when the collar of a shirt was worn, they would turn the back of it and use it in the past. Now we satisfy our desire after using it for a while before it gets old or we buy new ones to be fashionable"

He even tried to explain the ambiguity of the answer to the question "to whom planned obsolescence serves" by using the "chicken egg metaphor" while basing these statements:

"Is it because businesses want it? Or is it because we want it ourselves? We always have a desire to buy a new 
one, it can be said that this request is a behavior style that only appeals to the system. This consumption behavior continues as it suits both the producers and consumers."

It can be said that the claim that planned obsolescence is carried out with the aim of "advancing technology" or "contributing to the economy of the consumer" is not taken into account by some interviewees. I11 (Female, 32) brought the subject to a more explanatory definition framework with an example that confirms these statements:

"If I say that I buy a product without paying attention to its price, it would be a lie. I pay attention to his price. I do not have any problems with a product that I bought for a reasonable fee for many years. For that reason, a product I bought for a reasonable fee meets my needs. It gives me a chance to change when I'm bored".

It is explained in the statements of I1 (Male, 39) and 111 (Female, 32) that such problems are not experienced in the products they buy for high wages:

"If the manufacturer produces the product as a more durable product, it will do so at a different (extra) cost. If we want it to be durable, we prefer different brands. These brands are also more durable. This is about how much money we actually want to give. We buy products that are slightly less durable because we want to obtain them with less cost.

113 (Female, 30) cited as an example of the shopping she did with her husband and talked about how much they scrutinize during the shopping process. 113 (Female, 30) stated that "If I buy a product for less cost, I definitely use it knowing it will last for a little while. For this reason, I think it will last for many years when I give more money to products." I16 (Male, 35), using a statement against this, stated that this could not be true for "some products". "For example, even if a phone is given 20 thousand liras, I know that it has a life of 5 years and this cannot be changed."

It can be said here that there is an invisible agreement between consumers and producers. While consumers can use products with features, they may not have for a short time by paying less, manufacturers can sell products that they cannot sell with planned obsolescence when they set a high price. As an example of this situation, the experiences of 112 (Male, 29) can be given. 112 (Male, 29) bought a very cheap and lower model of a brand that can be bought for very high prices. According to him, the launch of this model is a marketing strategy that will convince those who want to use that brand but find the price too much. However, the 112 also stated that the phone has the same features as the higher model, but has some disadvantages such as "slowdown". In a sense, the concept of planned obsolescence can be associated with the consumer's "expectation" and "satisfaction".

Explaining her expectation from a product, 115 (Female, 29) explained that planned aging is not important for her. She stated that the place where the hood was in the kitchen was empty and did not look nice. For this reason, she said that she bought the cheapest hood that could both fill the space and be used when needed.

"It doesn't need to provide full performance for me. I do not have to use it for many years. The empty space in the kitchen bothers me and I want to fill it. That's why I bought the cheapest one. For example, there are products that I can buy for 3 thousand lira, but I preferred the one for 500 lira."

Such strategies are a feature of consumer culture. For example, 113 (Female, 30) tried to explain that planned obsolescence does not matter to the consumer in the case of "satisfaction" using the following statements:

"I like to buy certain brands. When I want to buy clothes and not from those brands but from other brands, they wear out in a short time. For a long time, I have not been shopping except for certain brands. In a sense, I am addicted to these brands. No matter how expensive they are, I still prefer those brands. Of course, there are different services that these brands offer me, I can also benefit from them."

114 (Female, 33) stated that he especially preferred some brands and brand loyalty stems from the need for "long-lasting use". I 14 (Female, 33) explained her "expectations" in consumption preferences with the following words: "I prefer the" quality "one. That's why I buy some brands because they are of high quality. I can say that the reason for this is that it provides long-lasting use in the product". I16 (Male, 35) explained his "expectations" in consumption preference using the following expressions. "... I prefer some products. For example, I care about my health. I make my preferences due to the fact that the products I prefer take into account what I care about".

It can be seen that for the interviewees, "brand loyalty" is related to "long-lasting use" and "personal tastes". For this reason, the "planned obsolescence" decision of the brand may affect some consumers, but not others. After all, if the consumer has different 
characteristics of the brand in mind, the consumer will not be affected by the planned obsolescence.

\section{"When it fails, we first check to see if there is a way to repair it."}

"Repairing" behavior, which goes against the logic of planned obsolescence, has emerged as a detail expressed by the interviewees. In fact, it was seen that the interviewees wanted to have a broken product repaired. Accordingly, interviewers prefer to have the product repaired when it malfunctions before it becomes obsolete. From this point of view, when interviewers were asked what "old" meant to them 19 (Male, 37) stated that "When it fails, we first check to see if there is a way to repair it. I care about how much money I spend and whether the product performs the way it used to" in a way that aggregates all interviewers'statements under a single answer. Perhaps interviewers often encounter products that malfunction before they become obsolete. In fact, interviewers change it most because it gives products a breakdown. This, in turn, indicates a planned obsolescence in the understanding that gives life to each product.

The part of the interviewees who think that they need to malfunction in order to have a new product, show us the "value" understanding they developed regarding the repair costs of the product and how this understanding has diversified. "When I want to have a product repaired, I want to deliver it to someone I trust, but I can say that the important thing for me is whether it will show the same performance again." 113 (Male, 29). As a result, while some interviewees explain the cost of repair by comparing the product price, some interviewees focus on performing the same task again without any trouble.

\section{DISCUSSION}

As a result of the interviews conducted in order to determine whether the concept of planned obsolescence is an opportunity for social and economic development or a trap set for the consumer, conclusions supporting both phenomena have been reached. Although a significant part of the interviewees emphasized the positive side of the concept, it was observed that a small number of the interviewees emphasized the negative features of planned obsolescence. The interviewees, who evaluated this concept as beneficial, emphasized the economic and social development aspects of planned obsolescence, highlighting the development of technology, ensuring social equality, enabling consumers to get rid of repair and maintenance costs, and especially for low-income groups to access goods and services. Various studies supporting these phenomena can be found in the literature. In this context, Grout and Park (2005) see planned obsolescence as a competitive tool for companies. Strausz (2009) thinks that planned aging is a means of punishing producers who sacrifice quality. Guiltinan (2008) considers planned obsolescence as a tool that enables innovations to spread to the whole society. Erdil and Tangıç (2019) evaluate planned obsolescence as a tool that reduces costs, uses parts cheaply, and increases mass production and consumption.

Emphasizing the negative side of planned obsolescence, the interviewees emphasized the aspect of the concept that exploits consumers by making them dependent, directs them to buy out of need, impoverishes the society, harms the environment, and leads people to various crimes by eroding their moral and intellectual values. The result, indicating that it especially directed people towards crime, was found to be quite remarkable. Various findings supporting this case have been reached in the literature. In this context, La Rosa (2020) saw the concept of planned obsolescence, which wasted resources and pushes consumers to buy constantly, as a harmful activity and stated that it could be considered a crime. Similarly, Albrecht (2019) stated that the phenomenon can be evaluated within the scope of public law and even criminal law. However, Proske et al. (2016) stated that consumers generally want to have more durable products. Cooper (2008b) and Echegaray (2016) stated that planned obsolescence should be avoided in order to ensure sustainable consumption. Bianchi (2018) considered it as a concept that increases the use of natural resources and creates environmental problems.

As a result of today's social structure, when the consumer purchases a product, he/she can also buy the underlying points. When the consumer expects a product to have a long life, the presence of "planned obsolescence" indicates that this is a desire that can be realized up to a certain point. The consumer will necessarily buy a new product after a while. This expresses the negative side of planned obsolescence for the consumer. Secondly, as can be seen in the statements of some interviewees, individuals can get bored of using the same product for a long time and may want to change this product. These expressions show that planned obsolescence is a positive aspect in terms of fulfilling the consumer's wishes. However, the idea of continuous consumption reveals the consumerism situation in which planned obsolescence leads 
individuals. It can be said that this situation, which can be interpreted both positively and negatively for the consumer, basically shows negative features. So much so that the consumer should be aware that he does not make a choice among consumption strategies that will result in negative consequences. This awareness can enable him to consume without further financial loss in the purchasing process. In future studies, it may be possible to create conscious consumers about planned aging with new interview designs that individuals can gain awareness.

\section{CONCLUSION}

As a result of the interviews, two approaches to the concept of planned obsolescence were identified in general. A significant part of the interviewees stated that the concept of planned obsolescence is necessary for social, economic, technological and ecological development. In this way, it has been stated that various values can be spread throughout the society. A small number of interviewers have stated that the concept contains a number of characteristics that pollute the environment, exploit consumers, waste resources and push people to crime.

As a result, we can say that planned obsolescence has multiple meanings both from the point of view of manufacturers and consumers. Here, it is noteworthy that the manufacturer tries to keep the consumer with different services, while diversifying what the consumer expects from the product. It can be said that planned obsolescence can determine the quality of the product, but it can also ensure poor quality. While the product can be used for many years, it may cause the product to deteriorate immediately. Obviously, in this process where the consumer produces multiple meanings, it has been observed that he welcomes the planned obsolescence when he "satisfies his desire" or "gets bored of using" the product.

Finally, based on the concept of "planned obsolescence", it can be said that an "invisible agreement" was made between the "producer and the consumer". So much so that even if the manufacturer changes the rules, some interviewers can continue their agreement with it because of their loyalty to the manufacturer. But the interviewer's effort to repair the "old" also shows that he is not blindly dragged into consumption. In a sense, the "expert consumer" tends to consume in a controlled manner.

In terms of guiding future studies, it is thought that it would be beneficial to analyze remarkable results such as "planned obsolescence and sustainability", "planned obsolescence and crime" "planned obsolescence and technological development" and "planned obsolescence and environment" in depth. Constructing the study only by interviewing experts is considered as an important constraint. This situation is seen as an important obstacle in generalizing the results to the whole population. In addition, various suggestions are offered for practitioners. Practitioners should work to eliminate the negative perception of the concept. In this context, it is necessary to work on ecological, life-friendly, robust, durable and less wasteful products that will minimize rapid obsolescence in the production process. It is thought that sustainable development can be achieved in this way. 


\section{References}

Akçay, V. H. (2018). Planlı eskitme stratejisi üzerine araştırmalar. Ankara: Gazi Kitapevi.

Adrion M. and Woidasky J. (2019). Planned obsolescence in portable computers - empirical research results-. In: Pehlken A., Kalverkamp M., Wittstock R. (Eds) Cascade Use In Technologies 2018 (pp. 13-20). Berlin: Springer Vieweg.

Albrecht E. (2019). Planned obsolescence: A case under torts law as intentional damage contrary to public policy (Art. 826 German Civil Code). In: Schmidt M., Giovannucci D., Palekhov D., Hansmann B. (Eds) Sustainable Global Value Chains. Natural Resource Management in Transition, (pp. 689-708). Cham: Springer.

Baudrillard, J. (2015). Tüketim toplumu. (Çev. H. Deliceçaylı ve F. Keskin), İstanbul: Ayrıntı Yayınları.

Bauman, Z. (2018). Kuşatılmış toplum. (Çev. A. E. Pilgir), İstanbul: Ayrıntı Yayınları.

Becher, S. I. and Sibony, A. L. (2020). Confronting product obsolescence. Columbia Journal of European Law, Forthcoming, 27(2), 1-50.

Bianchi, L. V. (2018). The influence of the principle of sustainable consumption over the combat against planned obsolescence, the guarantee of 'durable products' and the right to information of consumers in Argentina. Revista De Derecho Privado, (34), 277-310.

Bocock, R. (2014). Tüketim. (Çev. İ. Kutluk), Ankara: Dost Yayınları.

Brönneke, T. (2017). Premature obsolescence: suggestions for legislative counter-measures in German and European sales \& consumer law. Journal for European Environmental \& Planning Law, 14(3-4), 361-372.

Cooper, T. (2004a). Inadequate life? Evidence of consumer attitudes to product obsolescence. Journal of Consumer Policy. 27, 421-449.

Cooper, T. (2008b). Slower consumption: Reflections on product life spans and the "throwaway society". Journal of Industrial Ecology, 9 (1-2), 51-67.

Çerçi, M. (2019). Tüketicilerin planlı eskitmeye yönelik tutumları: Akıllı telefon tüketicileri üzerine bir araştırma. (Doktora Tezi). Marmara Üniversitesi Sosyal Bilimler Enstitüsü, İstanbul.

De Franceschi, A. (2018). Planned obsolescence challenging the effectiveness of consumer law and the achievement of a sustainable economy: The Apple and Samsung cases. Journal of European Consumer and Market Law, 7(6), 217-264.

Dimatteo, L. A. and Wrbka, S. (2018). Planned obsolescence and consumer protection: The unregulated extended warranty and service contract industry. Cornell JL \& Pub. Pol'y, 28, 483-554.

Erdil, P. A. and Taçgın, E. (2019, April). An overview of the planned obsolescence paradigm-marketing strategy: Evaluation via multiple criteria decision making methods for the sectors in Turkey. In International Congress of Management Economy and Policy 2019 (pp. 80-97). İstanbul: Spring Proceedings Book.
Featherstone, M. (2013). Post-Modernizm ve tüketim kültürü. (Çev. M. Küçük), İstanbul: Ayrıntı Yayınları.

Ferguson, H. (1996). The lure of dreams: Sigmund Freud and the construction of modernity. London: Routledge.

Fishman, A., Gandal, N. and Shy, O. (1993). Planned obsolescence as an engıne of technological progress. The Journal of Industrial Economics, 41(4), 361-370.

Fiske, J. (1999). Popüler kültürü anlamak. (Çev. S. İrvan), Ankara: Ark Yayınları.

Franzolin, C. J. (2020). Planned obsolescence resulting from electrical and electronic equipment: Waste rights and Brazil's national solid waste policy. In Sustainable Consumption (pp. 463-477). Cham: Springer,

Gecit, B. B. (2020). Planned obsolescence: A keyword analysis. Journal of Management. Marketing and Logistics (JMML), V.7(4), 227-233.

Grout, P. A. and Park, I. (2005). Competitive planned obsolescence. RAND Journal of Economics, 36(3), 596-612.

Guiltinan, J. (2008). Creative destruction and destructive creations: Environmental ethics and planned obsolescence. Journal of Business Ethics, 89, 19-28.

Hayes, D. (1978). Repairs, re-use, recycling: Moving towards a sustainable society. New Scientist, 79(1121), 869-872.

Kadıoğlu, Z. K. (2014). Tüketim iletişimi. İstanbul: Pales Yayınları.

Kamenar, M. (2020). E-Waste and obsolescence: Analysis of croatian consumers' habits and attitudes. (Doctoral Dissertation). University of Rijeka. Faculty of Economics and Business, Rijeci.

Kessler, T. and Brendel, J. (2016). Planned obsolescence and product-service systems: Linking two contradictory business models. JCSM, 8, 29-52.

Kinokuni, H., Ohori, S. and Tomoda, Y. (2019). Optimal waste disposal fees when product durability is endogenous: Accounting for planned obsolescence. Environmental and Resource Economics, 73(1), 33-50.

Kuik, S. and Diong, L. (2019). A model-driven decision approach to collaborative planning and obsolescence for manufacturing operations. Industrial Management \& Data Systems. 119(9), 1926-1946.

Kuppelwieser, V. G., Klaus, P., Manthiou, A. and Boujena, O. (2019). Consumer responses to planned obsolescence. Journal of Retailing and Consumer Services, 47, 157-165.

La Rosa, E. (2020). Planned obsolescence and criminal law: A problematic relationship?. In: Mauerhofer V., Rupo D., Tarquinio L. (Eds) Sustainability and Law. (pp. 221-236) Cham: Springer.

Latouche, S. (2009). Farewell to growth. (Çev. D. Mackey), Cambrigde: National Centre The Book.

Levy, S. J. (1959). Symbols for sales. Harvard Business Review, 37 (4), 117-119. 
Maitre-Ekern, E. and Dalhammar, C. (2016). Regulating planned obsolescence: A review of legal approaches to increase product durabilityand reparability in Europe. RECIEL, 25(3), 378-394.

Malinauskaite, J. and Erdem, F. B. (2021). Planned obsolescence in the context of a holistic legal sphere and the circular economy. Oxford Journal of Legal Studies, 00(0), 1-31.

Marcus, J. S. (2020). Promoting product longevity. How can the eu product safety and compliance framework help promote product durability and tackle planned obsolescence, foster the production of more sustainable products, and achieve more transparent supply chains for consumers?. Luxembourg: European Union.

Milchev, G. and Miltchev, R. (2018). Development of information technologies, planned obsolescence and modification of the life-cycle of the CAD/CAM/CAE systems. European Journal of Sustainable Development, 7(3), 217-217.

Neckel, A. and Boeing, R. (2019). Influence of online consumer innovativeness behavior in eletronic products on planned obsolescence process. Revista De Administração Da UFSM, 12(1), 1-13.

Nes, V. N., Cramer, J. and Stevels, A. (1999). A practical approach to the ecological lifetime optimization of electronic products. In Proceedings First International Symposium on Environmentally Conscious Design and Inverse Manufacturing (pp. 108-111). Tokyo, IEEE.

Özkan, P. and Yücel, E. K. (2020). Linear economy to circular economy: Planned obsolescence to cradle-to-cradle product perspective. In Handbook of Research on Entrepreneurship Development and Opportunities in Circular Economy (pp. 61-86). Pensilvanya: IGI Global.

Packard, V. (1960). The waste makers. New York: D. Mckay Co.

Paricio, J. M., Peña, J. A. and Miralbes, R. (2019). Well planned obsolescence and the eco-design. In Advances On Mechanics, Design Engineering And Manufacturing II (pp. 74-84). Cham: Springer.
Philip, R. S., Anian, A. M. and Raja, A. S. M. (2020). Planned fashion obsolescence in the light of supply chain uncertainty. Academy of Strategic Management Journal, 19(1), 1-17.

Proske, M., Winzer, J., Marwede, M., Nissen, N. F. and Lang, K. (2016). Obsolescence of electronics - the example of smartphones. Electronics Goes Green 2016+ (EGG) (pp. 1-8). Berlin: IEEE.

Robertson, R. (1995). Glocalization: Time-Space and homogeneity heterogeneity. In M. Featherstone et al. (Eds) Global Modernities, (pp. 25-44). London: Sage.

Satyro, W. C., Sacomano, J. B., Contador, J. C., and Telles, R. (2018). Planned obsolescence or planned resource depletion? A Sustainable Approach. Journal of Cleaner Production, 195, 744-752.

Sherif, Y. S. and Rice, E. L. (1986). The search for quality: The case of planned obsolescence. Microelectronics Reliability, 26(1), 75-85.

Sielska, A. (2019). Planned obsolescence: Gain or loss to the consumer? Scientific Papers of the Silesian University of Technology, 134, 215-224.

Sihvonen, L. (2020). "Classics age"- The flexibility of planned obsolescence in terms of the classic finnish board game kimble-. Wider Screen, 23(2-3), 1-26.

Slade G. (2006). Made to break: Technology and obsolescence in America. Cambridge: Harvard University Press.

Smeels, E. and Stevels, A. (2003). Influencing product lifetime through product design. proceedings of ecodesign. Third International Symposium On Environmental Conciousness Design and Inverse Manufacturing (pp. 267-271). Tokyo: Proceedings.

Strausz, R. (2009). Planned obsolescence as an incentive device for unobservable quality. The Economic Journal, 119(540), 1405-1421.

Zhao, Y., Wang, X., Jiang, Y., Wang, L., Singh, A.K., Huang, L. and Yang, M. (2021). An enhanced planned obsolescence attack by aging networks-on-chip. Journal of Systems Architecture, 117, 1-10. 